\title{
BMJ Open Cost-effectiveness of a repeat HIV test in pregnancy in India
}

\author{
Smita Joshi, ${ }^{1}$ Vinay Kulkarni, ${ }^{2}$ Raman Gangakhedkar, ${ }^{3}$ Uma Mahajan, \\ Sushma Sharma, ${ }^{4}$ Devendra Shirole, ${ }^{5}$ Nomita Chandhiok ${ }^{6}$
}

To cite: Joshi S, Kulkarni V, Gangakhedkar R, et al. Costeffectiveness of a repeat HIV test in pregnancy in India. BMJ Open 2015;5:e006718. doi:10.1136/bmjopen-2014006718

- Prepublication history for this paper is available online. To view these files please visit the journal online (http://dx.doi.org/10.1136/ bmjopen-2014-006718).

Received 23 September 2014 Revised 5 March 2015 Accepted 27 March 2015

\section{CrossMark}

${ }^{1}$ Department of Preventive Oncology, Hirabai Cowasji Jehangir Medical Research Institute (HCJMRI), Pune, Maharashtra, India

${ }^{2}$ Prayas Health Group, Amrita Clinic, Pune, Maharashtra, India

${ }^{3}$ National AIDS Research Institute, Pune, Maharashtra, India

${ }^{4}$ MIMER Hospital, Pune, Maharashtra, India

${ }^{5}$ Kamla Nehru Hospital, Pune Municipal Corporation, Pune, Maharashtra, India

${ }^{6}$ Indian Council of Medical Research, New Delhi, India

Correspondence to Dr Smita Joshi; smitanjoshi@gmail.com

\section{ABSTRACT}

Objective: To evaluate cost-effectiveness of second HIV test in pregnancy.

Background: Current strategy of single HIV test during pregnancy in India can miss new HIV infections acquired after the first test or those HIV infections that were missed in the first test due to a false-negative HIV test.

Methods: Between August 2011 and April 2013, 9097 pregnant HIV uninfected women were offered a second HIV test near term (34 weeks or beyond) or within 4 weeks of postpartum period. A decision analysis model was used to evaluate cost-effectiveness of a second HIV test in pregnant women near term.

Primary and secondary outcome: Our key outcome measures include programme cost with addition of second HIV test in pregnant women and quality-adjusted life years (QALYs) gained.

Results: We detected 4 new HIV infections in the second test. Thus HIV incidence among pregnant women was $0.12(95 \% 0.032$ to 0.297$)$ per 100 person women years (PWY). Current strategy of a single HIV test is 8.2 times costlier for less QALYS gained as compared to proposed repeat HIV testing of pregnant women who test negative during the first test. Conclusions: Our results warrant consideration at the national level for including a second HIV test of all pregnant women in the national programme. However prior to allocation of resources for a second HIV test in pregnancy, appropriate strategies will have to be planned for improving compliance for prevention of mother-to-child transmission of HIV and reducing lossto-follow-up of those women detected with HIV.

Trial registration number: CTRI/2013/12/004183.

\section{INTRODUCTION}

Mother-to-child transmission (MTCT) of HIV remains the most significant route of HIV infection among children in the developing countries. At the same time, of all the biological interventions to prevent HIV transmission, prevention of MTCT of HIV is the most efficacious intervention. The global plan towards elimination of new HIV infections among children has reported $38 \%$ decrease in new HIV infections among children. ${ }^{1}$ In

\section{Strengths and limitations of this study}

- Of all the biological interventions to prevent HIV transmission, prevention of mother-to-child transmission (PMTCT) of HIV is the most efficacious intervention.

- Our proposed strategy of a repeat HIV test in pregnancy near term is cost-effective and strengths of our study include large sample size and demonstration of low HIV incidence in pregnant women.

- The current strategy of a single HIV test results in 8.2 times more cost for less quality-adjusted life years gained. Our proposed strategy of repeat HIV testing of pregnant women who test negative in the first test offers 1 healthy child at US\$6.8.

- The limitations of the study include low HIV incidence and loss to follow-up. Therefore, prior to allocation of resources for a second HIV test in pregnancy, appropriate strategies will have to be planned for minimising such loss to follow-up.

the developed regions of the world, MTCT rates are as low as $2 \%$ due to wide coverage and provision of highly effective antiretroviral treatment (ART) regimens. ${ }^{2}{ }^{3}$ Eliminating paediatric HIV infection appears to be the most achievable goal globally.

In India, a Prevention of Parent to Child Transmission of HIV/AIDS (PPTCT) programme was initiated in 2002. Since then, there has been sustained scale up of the PPTCT programme in the country. Total annual births in 2009 in India were 26787 $000,{ }^{4}$ and the Interagency Task Team of UNICEF on the prevention and treatment of HIV infection in pregnant women, mothers and children estimated that of these 27 million annual pregnancies, 22 000-61 000 occurred in HIV-positive pregnant women. ${ }^{5}$ It is estimated by the National AIDS Control Organization (NACO) that $5.4 \%$ of the new HIV infections in India are due to transmission of infection from parent to child. ${ }^{6}$ The PPTCT programme of the NACO offers routine HIV testing to all pregnant mothers. As per the current protocol, women are 
tested for HIV only once during pregnancy. ${ }^{7}$ Therefore, pregnant women who are in the window period at the time of the first HIV test or who acquire HIV after the first test do not receive interventions to prevent transmission of HIV to the baby. Acute HIV infection is associated with very high levels of HIV-1 RNA, ${ }^{8}$ thus acute maternal HIV-1 infection during pregnancy and breastfeeding is associated with higher rates MTCT of HIV-1. ${ }^{10-12}$ The aim of eliminating MTCT of HIV will be accomplished only if appropriate strategies to prevent transmission are applied at each step. The Centre for Disease Control (CDC), USA, has recommended repeat HIV testing in the third trimester for all women in jurisdictions with elevated HIV incidence and for women receiving healthcare facilities with at least one diagnosed HIV case per 1000 pregnant women per year. ${ }^{13}$

A second HIV testing of pregnant women is not yet implemented in India. In addition to the already declining HIV epidemic and other competing health priorities, we are at the crossroads of carefully allocating available resources for HIV prevention efforts. In order to include a second HIV test of pregnant women in the national programme to achieve the goal of elimination of MTCT, a cost-effectiveness analysis of the intervention can help policymakers in taking an appropriate decision for implementation of the intervention. Therefore, we conducted a study to evaluate cost-effectiveness of an additional HIV test among pregnant women attending antenatal clinics in Pune, Maharashtra.

\section{METHODS}

The study was conducted at two Primary Health Centres (Kamshet and Talegaon in Maval Tehsil) and three urban sites (Maharashtra Institute of Medical Education and Research, Kamla Nehru Hospital and Sane Guruji Hospital).

The study was conducted between August 2011 and April 2013. Study staff was hired and trained prior to study initiation. Monthly data regarding number of pregnant women tested for HIV (1st HIV test as per national guidelines) and number detected with HIV (baseline HIV prevalence in pregnant women) were collected from the NACO ART centre at these sites.

Potential study participants were identified based on their antenatal chart review. Women in the late third trimester of pregnancy (beyond 34 weeks of pregnancy) with a documented HIV-negative test report at least 3 months prior to the visit, willing to sign a written informed consent form and willing to undergo a repeat HIV test, were consented and offered a second HIV test. Written informed consent included possibility of a telephonic call or a home visit if they were confirmed to be HIV infected so that PPTCT services could be offered. After signing the informed consent form, data were collected on a structured questionnaire regarding age, education, religion, marital status, occupation of both partners, age at first sexual contact, husband's risk for
HIV infection, history of any risk after the initial HIV test (history of blood transfusion, tattoo, ear/nose piercing, injections) and obstetrical history. A rapid HIV test was performed on a whole blood sample collected by a finger prick on site. Post-test counselling was carried out and an HIV test report was given to the woman immediately. As per the national protocol, women were also counselled to encourage their partners to get tested for HIV and to opt for an institutional delivery.

If the HIV test report was positive in the rapid HIV test, a second venous sample was immediately collected for confirmation of HIV infection and women were called back for the test report after 1 week. Women who were detected with HIV infection were referred appropriately for PPTCT interventions. Recently delivered women who could not be assessed by a second HIV test prior to delivery (eg, those who delivered on admission) but had a documented negative HIV test report at least 3 months prior to delivery, were also invited to participate in the study and were tested within 4 weeks of delivery so that possible infection could not be attributed to HIV acquisition after delivery.

\section{DATA ANALYSIS}

Data were collected on a structured questionnaire. Data entry was performed in MS Access 2007 software and analysed using STATA V.12.0 software. Standard formulae were used to calculate $95 \%$ CI. TreeAge software was used for cost-effectiveness and sensitivity analysis. The indicators of cost-effectiveness were programme cost with addition of a second HIV test in pregnant women and quality-adjusted life years (QALYs) gained. A decision analysis model was created to compare two strategies (figure 1): (1) the current strategy of a single HIV test during pregnancy that is implemented by NACO and (2) a proposed strategy with addition of a second HIV test of pregnant women after 34 weeks of pregnancy or within 4 weeks after delivery who were tested HIV negative in the first test (in addition to the current strategy of a single HIV test). The model was created for 9097 women enrolled in the study to compare proposed strategy with the current strategy. The model included four women who were HIV negative in the first test at baseline but were detected with HIV infection after 3 months in the second test and had an opportunity to prevent MTCT with the use of ART. We also compared HIV status of their babies and life expectancy of the HIV-infected baby with and without ART. Baseline values for input parameters for decision analysis model are given in table 1 . The programme costs included personnel, infrastructure, recurrent costs, cost of ART for PPTCT to women detected with HIV and treatment of the HIV-infected baby. For the current strategy, US\$3.33 was included as the cost of the first HIV test. ${ }^{14}{ }^{15}$ For the proposed strategy, the cost of the first HIV test as well as the second HIV test (US\$3.33 each) was included in the model (figure 1). The cost of the second HIV test for 


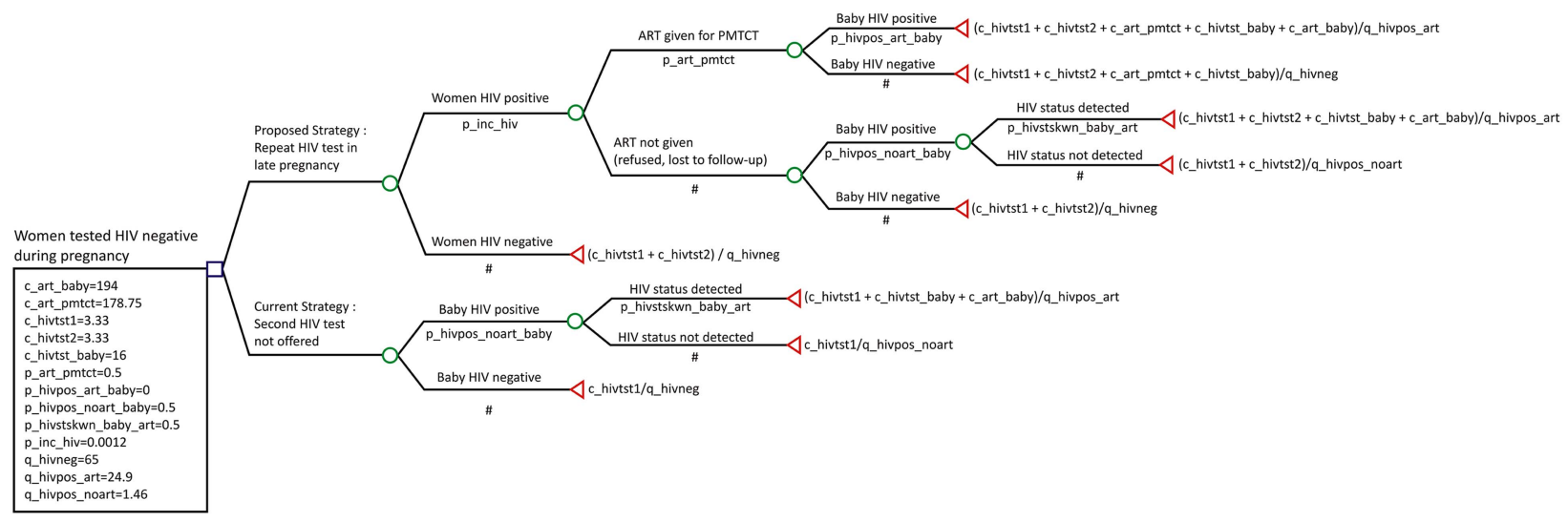

Figure 1 Decision analysis model showing comparison of cost-effectiveness of proposed strategy of repeat HIV testing of pregnant women in late pregnancy with the current strategy of single HIV test (ART, antiretroviral treatment; PMTCT, prevention of mother-to-child transmission).

the programme is likely to be less than US\$3.33, as the infrastructure already exists, however, for convenience, we have considered US\$3.33 for second test also to account for personnel time and cost. The probabilities of new HIV infections, ART for the mother and HIV status of the baby at the end of 18 months obtained from this study were used for decision analysis. We have assumed that life expectancy of an HIV-infected child in India on ART would be at least $50 \%$ of normal life expectancy, ${ }^{16}$ and since the life expectancy of a healthy baby in India is 65 years, ${ }^{17}$ for convenience, we rounded off the life expectancy to 30 years. Thus we included

\section{Table 1 Input parameters for decision analysis model}

\begin{tabular}{|c|c|c|}
\hline \multicolumn{2}{|l|}{ Variable (reference) } & \multirow[t]{2}{*}{ Comment } \\
\hline Life expectancy in years & & \\
\hline Life expectancy of a healthy baby ${ }^{17}$ & 65 & \\
\hline Life expectancy of an HIV-positive baby with $A R T^{16}$ & 30 & \\
\hline Life expectancy of an HIV-positive baby without $A R T^{27}$ & 2 & \\
\hline \multicolumn{3}{|l|}{ Probabilities } \\
\hline Probability of HIV incidence rate in pregnant women & $\begin{array}{l}0.0012 \\
(95 \% \mathrm{Cl} 0.00032 \text { to } 0.00297)\end{array}$ & $\begin{array}{l}\text { Based on new HIV } \\
\text { infections detected } \\
\text { during the second HIV } \\
\text { test in our study }\end{array}$ \\
\hline $\begin{array}{l}\text { Probability of receiving ART in women detected with HIV } \\
\text { in the second test }\end{array}$ & $0.5(95 \% \mathrm{Cl} 0.33$ to 0.964$)$ & $\begin{array}{l}\text { Based on our study } \\
\text { findings }\end{array}$ \\
\hline Probability of breast feeding & 1 & $\begin{array}{l}\text { Based on our study } \\
\text { findings }\end{array}$ \\
\hline \multicolumn{3}{|l|}{ Cost (US\$, US $\$ 1=50$ INR) } \\
\hline Cost of first HIV test ${ }^{14} 15$ & US\$3.33 & \\
\hline Cost of second HIV test ${ }^{14} 15$ & US $\$ 3.33$ & \\
\hline Cost of ART for PMTCT ${ }^{18}$ & US\$178.75 & \\
\hline Cost of HIV testing (HIV PCR) & US\$16.0 & $\begin{array}{l}\text { Based on cost to } \\
\text { Prayas's EGPAF's } \\
\text { PMTCT programme }\end{array}$ \\
\hline Cost of ART for HIV-infected baby ${ }^{18}$ & US\$194.0 & \\
\hline \multicolumn{3}{|l|}{ QALY } \\
\hline QALY of HIV uninfected baby ${ }^{19} 20$ & 1 & \\
\hline QALY of HIV-infected baby on ART 1920 & 0.83 & \\
\hline QALY of HIV-positive baby without $A R T^{19} 20$ & 0.73 & \\
\hline \multicolumn{3}{|l|}{ QALY gained } \\
\hline $\begin{array}{l}\text { QALY gained }{ }^{*} \text { for healthy baby (HIV uninfected/ } \\
\text { HIV-negative baby) })^{17}\end{array}$ & 65 & \\
\hline QALY gained for HIV-positive baby on $\mathrm{ART}^{20}$ & 24.9 & \\
\hline QALY gained for HIV-positive baby without $A R T^{20}$ & 1.46 & \\
\hline
\end{tabular}


cost of ART for an HIV-infected child ${ }^{18}$ for 30 years after birth. We assigned a QALY weight of 1 for a healthy child (HIV negative), 0.83 for an HIV-infected child with ART and 0.73 for an HIV-infected child without ART. ${ }^{19} 20$ The outcome in terms of QALY, costs and probability were entered into the TreeAge software for cost-effectiveness and sensitivity analysis. We performed one-way sensitivity analysis to determine the effect of HIV incidence on the cost-effectiveness of the programme.

\section{RESULTS}

We enrolled 9164 consecutive eligible women in this study of whom 67 were excluded from final analysis due to inadequate data and thus 9097 women were included in the final analysis. Of these 9097 women, 2229 and 6868 women were enrolled at rural and urban sites, respectively. The majority of the enrolled participants $(69.4 \%)$ were less than 25 years of age, $94.5 \%$ had some education and $79 \%$ of the participants were Hindu. None of them declined a second HIV test. About $90 \%$ were housewives and $99.4 \%$ were living with a husband who was earning. About $45.4 \%$ were primigravida and 99.9\% were not infected with HIV in the second HIV test. Table 2 provides data on enrolments at rural and urban sites, baseline HIV prevalence and HIV incidence in pregnant women. Baseline HIV prevalence in pregnant women (HIV prevalence in pregnant women during the first HIV test) at rural sites was 0.42 , and 0.46 at urban sites, and the difference was not statistically significant (data not shown). The overall HIV prevalence at baseline in pregnant women was $0.45 \%$.

We detected four new HIV infections among the pregnant women and thus HIV incidence among pregnant women was 1.2 per 1000 person women years (PWY) (95\% CI 0.32 to 2.97). Two women each were detected with new HIV infection in the second test at the rural and urban sites. HIV incidence at the urban sites was 0.8 (95\% CI 0.09 to 2.82) per $1000 \mathrm{PWY}$, and 2.3 (95\% CI 0.27 to 8.19$)$ per 1000 PWY at the rural sites. HIV incidence at the rural sites was higher than that of urban sites but the difference was not statistically significant.

Of the 9097 women included in the final analysis, 4 women were detected with HIV infection in the second HIV test as stated above. Their partners were also tested for HIV and all 4 were detected to be HIV infected. However, none of them were aware of their HIV status. All these four women were primigravida and their mean age was 27.25 (range 20-35 years). Of these four women, one refused to accept the test result and left the study. One woman defaulted on treatment for PPTCT and her baby was found to be infected with HIV at 12 months of follow-up. Two women completed ART for PPTCT and their babies remained HIV negative at 18 months. These transmission probabilities and aforementioned costs were used in the TreeAge software. On rollback, the cost of the proposed strategy, that is, addition of a second HIV test in late pregnancy, was US\$6.8 per 64.98 QALYs gained (equivalent to one healthy life of an HIV uninfected child) whereas the current strategy of single HIV test during pregnancy requires US\$55.83 per 39.09 QALYs gained. Thus the currently administered national strategy spends 8.2 times more US dollars for less QALYs gained.

\section{Sensitivity analysis}

One-way sensitivity analysis was performed to determine the changes in cost-effectiveness with different probabilities of HIV incidence, and is presented in table 3. Our HIV incidence was 0.12 per $100 \mathrm{PWY}$, and with different probabilities of HIV incidence ranging from 0.01 to 5.0 per $100 \mathrm{PWY}$, the proposed strategy remained costeffective with less US dollars spent and more QALYs gained.

\section{DISCUSSION}

Our study provides an important lead to strengthen NACO's programme for PPTCT. Addition of a second HIV test near term for pregnant women who had tested HIV negative in the first HIV test in pregnancy was found to be cost-effective. To the best of our knowledge, this is the first study in India that has evaluated costeffectiveness of a second HIV test among pregnant women. Current strategy of a single HIV test results in 8.2 times more cost for less QALYs gained as compared to the proposed repeat HIV testing of pregnant women. Our proposed strategy offers 1 healthy child at US\$6.8. Our proposed strategy is cost-effective only with addition of the cost of the second HIV test and without addition of incidental benefits of early HIV diagnosis of young

Table 2 Baseline HIV prevalence, enrolments at rural and urban sites, and HIV incidence in pregnant women

\begin{tabular}{lll}
\hline & Rural sites & Urban sites \\
\hline Number of women tested for first HIV test & 4803 & 13109 \\
Number of women detected with HIV in first HIV test & 20 & 60 \\
Baseline HIV prevalence (first HIV test) & 0.42 & 0.46 \\
Number of women enrolled for second HIV test & 2229 & 6868 \\
Number of women detected with HIV in second HIV tests & 2 & 2 \\
HIV incidence rate per 1000 persons women years (PWY) & $2.3(95 \% \mathrm{Cl} \mathrm{0.27} \mathrm{to} \mathrm{8.19)}$ & $0.8(95 \% \mathrm{Cl} \mathrm{0.09} \mathrm{to} \mathrm{2.82)}$ \\
Overall HIV incidence/1000 PWY & $1.2(95 \% \mathrm{Cl} \mathrm{0.32} \mathrm{to} \mathrm{2.97)}$ & \\
\hline
\end{tabular}


Table 3 One-way sensitivity analysis of cost and effectiveness of current strategy (of single HIV test) and proposed strategy (of addition of second HIV test during pregnancy)

\begin{tabular}{|c|c|c|c|c|c|}
\hline $\begin{array}{l}\text { HIV incidence } \\
\text { (probability) }\end{array}$ & Strategy & Cost (C) & Effect (E) & $\begin{array}{l}\text { C/E (USD per } \\
\text { QALY gained) }\end{array}$ & $\begin{array}{l}\text { Incremental } \\
\text { cost-effectiveness ratio }\end{array}$ \\
\hline \multirow[t]{2}{*}{0.0001} & Proposed & $\$ 6.67$ & 65.00 & 0.10265 & Cost saving \\
\hline & Current & $\$ 55.83$ & 39.09 & 1.42824 & \\
\hline \multirow[t]{2}{*}{0.005} & Proposed & $\$ 7.29$ & 64.93 & 0.11226 & Cost saving \\
\hline & Current & $\$ 55.83$ & 39.09 & 1.42824 & \\
\hline \multirow[t]{2}{*}{0.010} & Proposed & $\$ 7.91$ & 64.87 & 0.12188 & Cost saving \\
\hline & Current & $\$ 55.83$ & 39.09 & 1.42824 & \\
\hline \multirow[t]{2}{*}{0.015} & Proposed & $\$ 8.52$ & 64.80 & 0.13152 & Cost saving \\
\hline & Current & $\$ 55.83$ & 39.09 & 1.42824 & \\
\hline \multirow[t]{2}{*}{0.020} & Proposed & $\$ 9.14$ & 64.74 & 0.14118 & Cost saving \\
\hline & Current & $\$ 55.83$ & 39.09 & 1.42824 & \\
\hline \multirow[t]{2}{*}{0.025} & Proposed & $\$ 9.76$ & 64.68 & 0.15086 & Cost saving \\
\hline & Current & $\$ 55.83$ & 39.09 & 1.42824 & \\
\hline \multirow[t]{2}{*}{0.030} & Proposed & $\$ 10.37$ & 64.61 & 0.16056 & Cost saving \\
\hline & Current & $\$ 55.83$ & 39.09 & 1.42824 & \\
\hline \multirow[t]{2}{*}{0.035} & Proposed & $\$ 10.99$ & 64.55 & 0.17027 & Cost saving \\
\hline & Current & $\$ 55.83$ & 39.09 & 1.42824 & \\
\hline \multirow[t]{2}{*}{0.040} & Proposed & $\$ 11.61$ & 64.48 & 0.18001 & Cost saving \\
\hline & Current & $\$ 55.83$ & 39.09 & 1.42824 & \\
\hline \multirow[t]{2}{*}{0.045} & Proposed & $\$ 12.22$ & 64.42 & 0.18977 & Cost saving \\
\hline & Current & $\$ 55.83$ & 39.09 & 1.42824 & \\
\hline \multirow[t]{2}{*}{0.05} & Proposed & $\$ 12.84$ & 64.35 & 0.19955 & Cost saving \\
\hline & Current & $\$ 55.83$ & 39.09 & 1.42824 & \\
\hline
\end{tabular}

women and their partners. With current programme guidelines of offering lifelong ART to all pregnant and lactating mothers irrespective of $\mathrm{CD} 4$ counts, this becomes even more beneficial. It is also worth noting that we detected one woman with HIV infection on the second day of her delivery. Thus repeat HIV testing should be offered to women in the immediate postpartum period if the second test was not performed prior to delivery or if they were never tested before.

During 2012, about 5.71 million pregnant women were tested for HIV in India. The overall HIV prevalence in India among them was $0.17 \%$, while in Maharashtra it was $0.23 \% .^{21}$ We observed higher prevalence of HIV $(0.45 \%)$ in pregnant women at our study sites. A wide variation of HIV prevalence among antenatal women has been reported across different states in India with lowest HIV prevalence of $0.02 \%$ in Arunachal Pradesh, Jammu and Kashmir, and highest prevalence of $0.84 \%$ in Nagaland.

Similarly, HIV incidence among pregnant women is likely to vary across different states/sites within India. Our study indicates that repeat HIV testing is costeffective even with very low HIV incidence $(<0.0001)$, and this strategy can be implemented and would be beneficial for all the states in India.

Although we could not ascertain whether all four new HIV infections were acquired after the first test (since we did not perform detuned ELISA on the samples); and it is possible that the first HIV test during pregnancy was a false-negative test. Considering our HIV incidence of 1.2 per $1000 \mathrm{PWY}$, a substantial number of new HIV-infected pregnant women could be detected with the proposed strategy of a second HIV test, and this opportunity for prevention of mother-to-child transmission (PMTCT) should not be missed if India wishes to achieve the goal of zero new HIV infections.

An important finding of this study is the low incidence of HIV in pregnant women, which supports other studies in demonstrating a decline in the HIV epidemic in India. Decline in adult HIV prevalence and new HIV infections are sustained in most of the states in India including all the high prevalence states of South India and the North East except for some low prevalence states. ${ }^{22} \mathrm{~A}$ report from Pune region has reported a decline in HIV incidence in young pregnant women and the estimated HIV incidence decreased from 2.2 (95\% CI 1.6 to 3.0 ) in 2002-2003 to 0.73 per 100 PWY (95\% CI 0.5 to 1.0 ) in $2006 .{ }^{23}$ We have previously reported $82 \%$ decline in HIV prevalence in pregnant women from 2003 to 2008 in the same region. ${ }^{24}$ In our study, HIV incidence was 0.12 per100 PWY and this also supports decline in new HIV infections among young pregnant women.

In our study, the male partners of women newly detected with HIV were encouraged to get tested for HIV after appropriate pretest counselling and all four male partners were also found to be HIV infected. They were referred appropriately and this additional benefit of early diagnosis, referral and linkage to treatment 
provides additional collateral benefit and addition to cost-effectiveness of our proposed intervention. Spread of HIV among married monogamous women from partners with high-risk behaviour has been previously reported..$^{25}$ It is possible that increased male partner involvement, counselling and testing of male partners at the time of first test could avert some of the transmissions to women, and consequentially to their children.

The strengths of our study include large sample size, demonstration of incident HIV infections in pregnant women who were tested HIV negative in the first HIV test in pregnancy and cost-effectiveness of repeat testing for HIV in pregnancy in spite of low incidence of HIV. This is probably because of substantial reduction in the cost of HIV testing as against the cost of lifelong ART if infected with HIV. The weaknesses of the study include low HIV incidence and loss to follow-up. Although we detected four new HIV infections in pregnant women, only two women completed appropriate ART for PMTCT and their babies remained HIV uninfected at the end of 18 months. Therefore, prior to allocation of resources for a second HIV test in pregnancy, appropriate strategies will have to be planned for minimising such loss to follow-up.

In addition to $\mathrm{CDC},{ }^{13}$ rescreening of pregnant women in the last trimester has been recommended by the South African government. ${ }^{26}$ South Africa is a country with very high HIV prevalence as well as HIV incidence. The cost-effectiveness of HIV re-screening during pregnancy in South Africa was shown to prevent a substantial number of infant HIV infections and save costs to the healthcare system. ${ }^{19}$ Our findings will help NACO in shaping the national policy for strengthening the PMTCT programme.

Acknowledgements The authors would like to thank authorities at the Pune Municipal Corporation, Sane Guruji Hospital, Kamla Nehru Hospital, Taluka Medical Office, Maval Taluka and The District Health Officer of Pune for allowing us to conduct this study at various study sites. We also thank our staff members for their tireless efforts to complete this large study. The authors thank the Director and other staff members of HCJMRI for the administrative and logistic support. We sincerely thank Dr Kenneth Freedberg, professor of Medicine at Harvard Medical School and Director of the Program in Epidemiology and Outcomes Research at the Harvard Medical School's Division of AIDS, and Director of the HIV Research Program in the Division of General Medicine at Massachusetts General Hospital for his review and suggestions for the manuscript.

Contributors SJ and VK designed, implemented the study, analysed the data and prepared the manuscript. RG, UM, SS, DS and NC analysed data and prepared the manuscript. All authors have approved the final submitted version.

Funding This study was funded by the Indian Council of Medical Research (IRIS ID number 2010-08370).

\section{Competing interests None declared.}

Patient consent Obtained.

Ethics approval The study was approved by the Ethics Committee of Hirabai Cowasji Jehangir Medical Research Institute (HCJMRI) and Jehangir Clinical Development Centre (JCDC)

Provenance and peer review Not commissioned; externally peer reviewed.

Data sharing statement No additional data are available.
Open Access This is an Open Access article distributed in accordance with the Creative Commons Attribution Non Commercial (CC BY-NC 4.0) license, which permits others to distribute, remix, adapt, build upon this work noncommercially, and license their derivative works on different terms, provided the original work is properly cited and the use is non-commercial. See: http:// creativecommons.org/licenses/by-nc/4.0/

\section{REFERENCES}

1. UNAIDS. Global plan towards the elimination of new HIV infections among children by 2015 and keeping their mothers alive. 20112015. http://www.unaids.org/en/media/unaids/contentassets/ documents/unaidspublication/2011/20110609_jc2137_global-pla

2. Mofenson LM. Successes and challenges in the perinatal HIV-1 epidemic in the United States as illustrated by the HIV-1 serosurvey of childbearing women. Arch Pediatr Adolesc Med 2004;158:422-5 (cited 21 Jul 2013).

3. European Collaborative Study. Mother-to-child transmission of HIV infection in the era of highly active antiretroviral therapy. Clin Infect Dis 2005;40:458-65 (cited 21 Jul 2013).

4. India PMTCT Factsheet: UNICEF. http://www.unicef.org/aids/files/ IndiaFactsheet_PMTCTFactsheet_2010.pdf (accessed 5 Oct 2013).

5. Factsheets on the status of national PMTCT responses in the most affected countries. The Interagency Task Team on the prevention and treatment of HIV infection in pregnant women, mothers and children (cited 25 Aug 2013). http://www.emtct-iatt.org/countries/india/

6. NACO. Annual CMIS Bulletin 2008-09. NACO, Department of AIDS Control, Ministry of Health and Family Welfare, Government of India. http://aidsdatahub.org/dmdocuments/NACO_Annual_CMIS_ BULLETIN_2008-09.pdf (accessed 5 Oct 2013).

7. National AIDS Control Organisation. Ministry of Health \& Family Welfare. Govt. of India. Antiretroviral Therapy Guidelines for HIVInfected Adults and Adolescents Including Post-exposure Prophylaxis. May 2007. http://www.naco.gov.in/NACO/About_NACO/ Policy_Guidelines/Policies_Guidelines1/ (accessed 5 Oct 2013).

8. Garcia PM, Kalish LA, Pitt J, et al. Maternal levels of plasma human immunodeficiency virus type 1 RNA and the risk of perinatal transmission. Women and Infants Transmission Study Group. N Engl J Med 1999;341:394-402 (cited 6 Sep 2013).

9. Lindbäck S, Karlsson AC, Mittler J, et al. Viral dynamics in primary HIV-1 infection. Karolinska Institutet Primary HIV Infection Study Group. AIDS 2000;14:2283-91 (cited 6 Sep 2013).

10. Dunn DT, Newell ML, Ades AE, et al. Risk of human immunodeficiency virus type 1 transmission through breastfeeding. Lancet 1992;340:585-8 (cited 6 Sep 2013).

11. Gray $\mathrm{RH}$, Li X, Kigozi G, et al. Increased risk of incident HIV during pregnancy in Rakai, Uganda: a prospective study. Lancet 2005;366:1182-8 (cited 6 Sep 2013).

12. Cao Y, Krogstad P, Korber BT, et al. Maternal HIV-1 viral load and vertical transmission of infection: the Ariel Project for the prevention of HIV transmission from mother to infant. Nat Med 1997;3:549-52 (cited 6 Sep 2013).

13. Branson BM, Handsfield HH, Lampe MA, et al. Revised recommendations for HIV testing of adults, adolescents, and pregnant women in health-care settings. MMWR Recomm Rep 2006;55:1-17;quiz CE1-4 (cited 21 Jul 2013). http://www.ncbi.nlm. nih.gov/pubmed/16988643

14. Dandona L, Kumar SP, Ramesh Y, et al. Changing cost of HIV interventions in the context of scaling-up in India. AIDS 2008;22 (Suppl 1):S43-9 (cited 17 Apr 2014).

15. Venkatesh KK, Becker JE, Kumarasamy N, et al. Clinical impact and cost-effectiveness of expanded voluntary HIV testing in India. PLOS ONE 2013;8:e64604 (cited 17 Apr 2014).

16. Aledort JE, Ronald A, Le Blancq SM, et al. Reducing the burden of HIV/AIDS in infants: the contribution of improved diagnostics. Nature 2006;444(Suppl 1):19-28.

17. WHO. Global Health Observatory (GHO). Country statistics (India). World Health Organization. http://www.who.int/gho/countries/ind/en/

18. WHO. Use of antiretroviral drugs for treating pregnant women and preventing HIV infection in infants. World Health Organization (cited 17 Apr 2014). http://www.who.int/hiv/pub/mtct/programmatic update2012/en/

19. Soorapanth S, Sansom S, Bulterys M, et al. Cost-effectiveness of HIV rescreening during late pregnancy to prevent mother-to-child HIV transmission in South Africa and other resource-limited settings. $J$ Acquir Immune Defic Syndr 2006;42:213-21 (cited 6 Oct 2013).

20. Sanders GD, Bayoumi AM, Sundaram V, et al. Cost-effectiveness of screening for HIV in the era of highly active antiretroviral therapy. N Engl J Med 2005;352:570-85 (cited 24 Mar 2014).

21. National AIDS Control Organisation. Annual Report 2012-13. Department of AIDS Control, Ministry of Health and Family Welfare (cited $18 \mathrm{Apr}$ 
2014). http://www.naco.gov.in/NACO/Quick_Links/Publication/Annual_ Report/NACO_Annual_Report/Annual_Report_2012-13/

22. WHO I Map gallery. World Health Organization, 2012 (cited 18 Dec 2012). http://www.who.int/gho/map gallery/en/

23. Gupte N, Sastry J, Brookmeyer R, et al. Declining HIV infection rates among recently married primigravid women in Pune, India. $J$ Acquir Immune Defic Syndr 2007;45:570-3 (cited 6 Oct 2013).

24. Kulkarni V, Joshi S, Gupte N, et al. Declining HIV prevalence among women attending antenatal care in Pune, India. Trans $R$ Soc Trop Med Hyg 2011;105:315-19 (cited 6 Oct 2013).
25. Gangakhedkar RR, Bentley ME, Divekar AD, et al. Spread of HIV infection in married monogamous women in India. JAMA 1997;278:2090-2 (cited 2 Mar 2014).

26. PMTCT Guidelines 2013 | Health Systems Trust. The South African Antiretroviral Treatment Guidelines 2013. PMTCT Guidelines: Revised March 2013 (cited 18 Apr 2014). http://www.hst.org.za/ publications/pmtct-guidelines-2013

27. Newell ML, Coovadia H, Cortina-Borja M, et al. Mortality of infected and uninfected infants born to HIV-infected mothers in Africa: a pooled analysis. Lancet 2004;364:1236-43 (cited 17 Apr 2014). 